\title{
Workshop as a Relevant Means of Interactive Teaching
}

\author{
Ani Manukyan \\ Yerevan State Pedagogical University \\ "Men must be taught as if you taught them not, \\ And things unknown posed as things forgot". \\ Alexander Pope
}

$\mathrm{M}$ odern pedagogical approaches provide new and exciting opportunities for educators to review their methods of teaching. The teachers' goal should be raising happy, healthy and productive citizens who can contribute to society and exhibit love for learning. This goal cannot be reached without carefully planned checkpoints along the way of learning.

The way we learn often determines the quality and usefulness of the knowledge gained. Some argue, that only learning from experience leads to usable knowledge. However, learning only by experience without the benefit of structural education of training, is a slow "hit and miss" process. Without the structure and direction of workshops and formal training programs, there is no way to be sure experience is providing all the important learning we need.

It is easy for us, educators to get caught in the cycle of performing our day-to-day activities. We get into a teaching routine and rarely stop to think about why we teach the way we teach or if our lessons are designed, implemented and assessed with purpose. We must possess a core set of beliefs that all children deserve respect and a chance to have a better life through the gift of learning. We must furthermore realize that it is the responsibility of the teacher to be a child advocate and encourage him to express his ideas on any information given, have opinion about everyday issues and up-to-date topics of international interest and investigate familiar subjects from new angles. Engaging the learners in the process of learning and providing a springboard for their own ideas and communicative needs should be the teachers' main purpose. One of the promising ways to catch up with this purpose is organizing workshops on various themes and stimulate students to debate, discuss and enjoy the process.

Workshop is one of the most instinctive features among the human beings as seldom do we accept anything without any argument or discussion about its implications. But still we do not give debating and discussion its due importance as an art which can help in the development of a personality and help an individual to instill confidence in himself. The practical usage of workshops is incredible as it is required for a lawyer in court, as well as a politician in political rallies, as well as in the parliament to take up against the attack of the opposing party (Mellander 1993:47-50). Even educational systems of many countries recognize the importance of constructive workshops and debating and that is why workshops are a regular fixture in many countries' school curriculum.

Teachers as workshop leaders need to understand how people learn in order to fully appreciate and apply new interactive methods of teaching. They should be guides, coach- 
es, facilitators, and democratic leaders as opposed to traditional leaders. Rather than simply presenting material to a captive and passive audience, you deal with participants who are active, involved and who are able to withdraw their own conclusions. They should assist participants to create and discover their own opinions and insights, help participants to find words for things that they already understand intuitively (Kolb 1985:122148). For democratic leadership to be possible, the assumption must be made that participants will be motivated to learn, think, contribute and act appropriately. The group must be willing to work as one.

For learning to occur, workshop leaders need to:

- encourage questioning and answering questions from their own experience,

- provide a supportive and challenging workshop climate,

- do away with any sort of punishment and overlook mistakes, because they create differences, and differences enable learning.

Here are some principles that workshop leaders should take into consideration:

- learning is unique to each individual. Every person learns at his own pace and his own way.

- learners want workshops focused on real life here-and-now problems and tasks, rather than on academic situations.

- the material has to be provided in manageable steps. In this way learners understand as they learn, and gradually come to master the complete task.

- learners need positive reinforcement when they first practice a new skill.

Workshop leaders need to avoid:

- taking themselves too seriously,

- acting defensively when challenged,

- answering a learner's question before allowing other learners to respond,

- speaking too long,

- asking closed ended questions even though more group input is needed.

If we don't want to live in a dictatorship, we must be vigilant to preserve our freedom. If we wish to preserve our freedom, we must be informed on the issues which require that we become acquainted with alternative points of view. The history of the development of civilization can be seen as the history of workshops on issues (Weisboard 1989:35). In democratic societies, there must be public debating and interactive workshops and we must keep in our minds that constructive debating is an art. With all this in mind, the following suggestions are offered.

\section{Learning Objectives}

- Select and apply appropriate methods of communication in various experiences.

- Work collaboratively with others.

- Approach communication experiences (both sending and receiving) as active, thinking participants.

- Manage time and resources when planning communication experiences.

- Solve problems and make decisions as part of the communication process.

- Consider various types of reasoning. 
- Consider various appeals to an audience.

- Consider the communicator's moral and ethical responsibilities.

- Demonstrate the ability to find and select relevant text.

- Speak to clarify and extend thinking.

- Speak to persuade, demonstrate, or entertain.

- Attend to voice, body language, and delivery of oral presentations.

- Set clear objectives for speaking and organize talks in a logical manner.

- Present arguments and information comprehensively and in a logical manner.

- Participate in oral communication experiences by listening critically and attentively.

- Listen to make connections, interpret, or infer.

- Listen to confirm, summarize, question, or predict.

- Recognize speaker's purpose, attitude, tone, and bias.

- Analyze the way in which topics are organized and identify speakers' techniques.

For democratic leadership to be possible, the assumption must be made that participants will be motivated to learn, think, contribute, and act appropriately. The group must be willing to work and learn together to achieve a given outcome (e.g. solve a problem, plan a programme, initiate a project) (Smith 1982:76-78).

Here are some 5 steps to help the teachers to reach all of the learners in the class.

Step 1: Setting the classroom stage - See how the classroom climate affects the needs of a variety of learners. See ways to build a learning community where all learners are accepted and respected.

Step 2: Knowing the players- Understand the critical need to appreciate the variety of student learning preferences. Gain a variety of strategies for determining students' strengths and styles.

Step 3: Working and altering the scripts - Know that alternative lesson formats will be necessary for reaching every student.

Step 4: Changing the set - Realize that some students will need to be shown information in different ways to be able to fully grasp the concept. See how to present lessons in unique ways that will help visual, logical, spatial, auditory and kinesthetic learners.

Step 5: Getting and giving feedback - Last but not least, see how to effectively assess the learner through appropriate feedback. See how to create and carry out assessment to determine learning progress (Smith 1982:64-66).

When two or more people have a conversation in which they support contradictory ideas there is always a lot of tension and, of course, many factors that can prevent them from reaching a common point. The difficulty is that there is a very thin line on which you can step: you need to be strong and convincing in order for the other person to accept your statement, but at the same time avoid trying to impose your thoughts by any means.

Moreover, you need to do all this and simultaneously use only rational arguments to 
ensure that the conclusion of the conversation is adopted by the other person. Emotional arguments are difficult to use because people have different emotions about the same things or events. Therefore, at the end of the discussion there is no certainty that both members have the same understanding of the subject.

One of the biggest mistakes that prevent an interactive workshop from achieving its main goal is the reason why some people engage in it. These are the ones who participate in it only for "winning", but let's not forget that it is not a competition. They are not actually interested in putting a theory or statement to the test and analyze it from an intellectual prospective. They just want to hear those magic words: "You are right!" Even if somewhere deep down they share your opinion, consciously or unconsciously, they will still contradict you. We may be tempted to think "Well, I know a person just like that", but the truth is that we all are like that from time to time. It might have something to do with the education we received in school. In the educational system teachers give pupils certain tasks, one of which is to try and come up with arguments in favor of a solution chosen by a character from a novel, for example, even if they do not approve of his actions. This type of exercise can help pupils develop their critical thinking but it can also unconsciously teach them to either support or reject a statement according to their needs. Therefore they can find it useful to reject an idea in a conversation with "person A" and then turn around and actively support the same idea in a conversation with "person B". Even if both persons are in the conversation for the right reasons they are still vulnerable to mistakes (Kennedy 1993:93-96).

Consciously or unconsciously, students use false arguments, here are the most common of them:

\section{False generalization:}

First of all, we have false generalization, of which there are two types: illegal induction and incomplete enumeration.

- Illegal induction is sometimes called rash generalization and it is used on a daily basis. E.g. Mark and Jane beat their children, therefore all parents do.

- Incomplete enumeration is also common and can prevent reaching a proper conclusion: In a presumable situation $A$ water extinguished fire. In a situation $B$ water again extinguished fire. Therefore, in all situations water extinguishes fire. (this is clearly false because despite the fact that in almost all situations water does extinguish fire there are some exceptions).

\section{Authority argument:}

Then, there is the authority argument. Again a very simple one: statement $A$ is true because (e.g. Freud)... says it is. Just by involving Einstein or Kant in the conversation does not mean you are using rational arguments.

\section{The "ad hominem" argument:}

Another false argument is the so called "ad hominem argument". In this case, a person will attack the other person's shortcomings: $2+2$ does not equal 5 because you are drunk. 


\section{The "majority rules" argument:}

A very popular argument is the "majority rules" argument: If 10,000 people say that a statement is true, then it has to be true. One more false attempt to be rational is the traditional: This statement is true because you cannot prove it is false.

There are of course many more false arguments, but the ones mentioned are the most common.

A workshop leader's attitude is infectious: if teachers are focused, interested and enjoy their work, learners will likely do the same. It's important to enjoy the adventure of teaching and learning, have a strong sense of yourself, your values and world outlook.

\section{References:}

1. Kennedy, P. (1993) Preparing for the Twenty First Century. Toronto: Harper Collins.

2. Kolb, D.A. (1985) Learning-style Inventory. // Self Scoring Inventory and Interpretation Booklet. Boston: Prentice Hall.

3. Mellander, K. (1993) The Power of Learning. // Fostering Employee Growth. Tilburg: MesoConsult.

4. Smith, R.M. (1982) Learning How to Learn. // Applied Theory for Adults. New York: Cambridge Book.

5. Weisboard, M.R. (1989) Productive Workplaces. // Organizing and Managing for Dignity, Meaning and Community. San Francisco: Jossey-Bass.

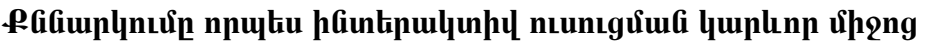

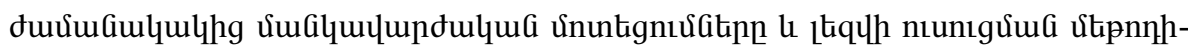

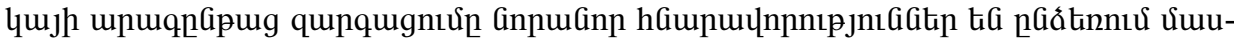

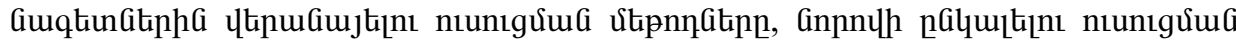

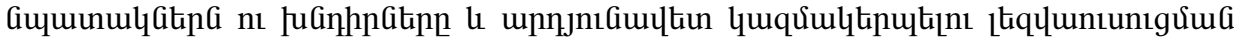
qnnəzipugn:

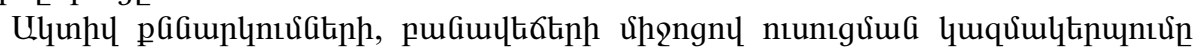

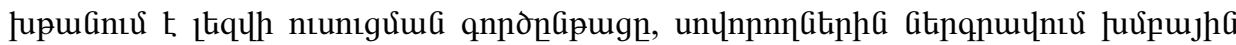

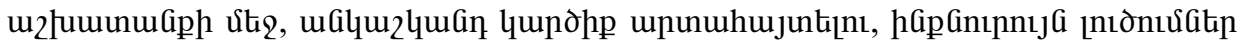
qunlitınt hGumuцnnnıpjnıti t. unuцhu: 